\title{
Inhibitory Effect of Retinoids on Alkaline Phosphatase Isoenzymes Activity in Human Serum
}

\author{
Seung Hee Kim ${ }^{1}$ and Ki-Young Moon ${ }^{2, \dagger}$ \\ ${ }^{I}$ Department of Dental Hygiene, Gwangju Health University, Gwangju 62287, Korea \\ ${ }^{2}$ Department of Clinical Pathology, Gwangju Health University, Gwangju 62287, Korea
}

\begin{abstract}
Changes in the activity of alkaline phosphatase (ALP) isoenzymes and isoforms in human serum have a major diagnostic value, therefore the regulation of ALP activities is a valuable target for therapeutic interventions. To assess the pharmacological activity of retinoids, i.e., all-trans retinoic acid and 13-cis retinoic acid, their tissue-specific inhibitory effect on human serum ALP activity was elucidated by chemical inhibition methods, heat-sensitive inactivation, and wheat-germ lectin precipitation test. Retinoids showed significant inhibition of the total ALP activity in human serum at a concentration of $5 \mathrm{mM}$. All-trans retinoic acid $(5 \mathrm{mM})$ and 13-cis retinoic acid $(5 \mathrm{mM})$ inhibited ALP activities by up to $12 \%$ and $15 \%$, respectively, compared to that by guanidine hydrochloride (200 mM). L-phenylalanine (100 $\mathrm{mM})$ and urea $(30 \mathrm{mM})$ had no further inhibitory effect on ALP activities in human serum pretreated with retinoids $(5 \mathrm{mM})$. Retinoids significantly inhibited ALP activities by up to $20 \%$ compared with that of tetramisole ( $30 \mathrm{mM}$ ). The ALP activities in retinoid-pretreated serum remained unchanged after the heat inactivation process. These results suggest that retinoids are inhibitors of the intestinal ALP isoenzyme. Remarkably, retinoids revealed potent inhibitory activities against ALP in wheat-germ lectin precipitant serum, indicating that they also function as inhibitors of the bone ALP isoform. The results show that retinoids inhibit the specific tissue-derived human serum ALP activities, moreover, the inhibitory effect of retinoids against bone ALP activity suggests their clinical utility as monitoring and prevention of metastasis of bone cancer.
\end{abstract}

Key Words: All-trans retinoic acid, 13-cis retinoic acid, Human serum alkaline phosphatase isoenzymes, Tissue-specific alkaline phosphatase

\section{INTRODUCTION}

The changes in the activities of isoenzymes and isoforms of alkaline phosphatase (ALP) in human serum have important diagnostic value, and disease-related changes in human serum ALP activity reflect disease processes (Epstein et al., 1986). An increased activity of ALP isoenzymes has been reported in various diseases of the digestive tract (Dent et al., 1968) and cirrhosis of the liver (Stolbach et al., 1967), as well as in chronic hemodialysis (Walker, 1974). Thus, the regulation of ALP activities is a valuable target for therapeutic interventions. The human alkaline phosphatase, a ubiquitous membrane-bound glycoprotein, is a metalloenzyme that exists as multiple isoenzymes in which heterogeneity is partly due to genetic factors and partly to post translational modifications. Human ALP is present as four isoenzymes depending upon the tissue that are intestinal ALP, placental

*Received: August 8, 2017 / Accepted: August 28, 2017

${ }^{\dagger}$ Corresponding author: Ki-Young Moon. Department of Clinical Pathology, Gwangju Health University, Gwangju 62287, Korea. Tel: +82-62-958-7621, Fax: +82-62-958-7526, e-mail: kmoon@ghu.ac.kr (C) The Korean Society for Biomedical Laboratory Sciences. All rights reserved.

(C) This is an Open Access article distributed under the terms of the Creative Commons Attribution Non-Commercial License (http://creativecommons.org/licenses/by-nc/3.0/) which permits unrestricted non-commercial use, distribution, and reproduction in any medium, provided the original work is properly cited. 
ALP, germ-cell ALP and tissue nonspecific alkaline phosphatases; i.e., liver, bone, and kidney ALP (Moss, 1982; Crofton, 1982; Seargeant and Stinson, 1979).

Retinoids, natural and synthetic derivatives of vitamin A, are important factors in the control of cell growth and differentiation, apoptosis, transcriptional activity, and carcinogenesis (Ertesvag et al., 2009; Paillaud et al., 2002; Darwiche et al., 2005; Moon, 2007). In addition, they take part in the expression of hundreds of genes, including enzymes, structural proteins, cell-surface receptors, neurotransmitters, and neuropeptide hormones (Balmer and Blomhoff, 2002). The actual or potential use of retinoids as immunomodulators or tumour-suppressive agents has been described (Carratu et al., 2012).

To assess the pharmacological activity of retinoids, their effect on ALP activity in human serum was evaluated, as little attention has focused on the regulatory effect of retinoids on human serum ALP activity induced. Therefore, the ability of all-trans retinoic acid (tretinoin) and 13-cis retinoic acid (isotretinoin) to regulate total ALP activity and the various ALP isoenzymes and isoforms in human serum were examined using four selective chemical inhibition methods; i.e., guanidine hydrochloride, L-phenylalanine, urea, and tetramisole. Heat-sensitive inactivation and the wheatgerm lectin precipitation test were used to differentiate the tissue origins of ALP. This study reports the inhibition by retinoids of human serum ALP isoenzymes and isoforms, and the usefulness of all-trans retinoic acid and 13-cis retinoic acid as regulators of specific organ-derived ALP isoenzyme activities in human serum.

\section{MATERALS AND METHODS}

\section{Chemicals and materials}

Lyophilized serum of human origin was obtained from Linear Chemicals (Barcelona, Spain), and were dissolved in distilled water to make a $5 \mathrm{~mL}$ solution. This human multisera control offers two different levels of concentration: Normal and Abnormal. The total ALP activity in human multisera normal and abnormal was 58 $12 \mathrm{U} / \mathrm{L}$ and $297 \pm$ $74 \mathrm{U} / \mathrm{L}$ that was assayed by p-nitrophenylphosphate AMP method, respectively.
A Great EscAPe Fluorescence detection kit for determination of alkaline phosphatase activity was obtained from Clontech Laboratories (Palo Alto, CA, USA). All-trans retinoic acid (vitamin A acid; tretinoin), 13-cis retinoic acid (isotretinoin) and lectin (Triticum vulgaris, wheat germ) were obtained from Sigma Chemical Co. (St. Louis, MO, USA). All other chemicals and solvents were purchased from Aldrich Chemical Co. (Milwaukee, WI, USA). Retinoids were diluted with $0.1 \mathrm{~N} \mathrm{NaOH}$ to derive a stock solution, and then directly added to the human serum. Spectrophotometric analysis of ALP activities was performed on a DR/ 4000U UV-Vis spectrophotometer (HACH Co., Loveland, CO, USA).

\section{Colorimetric assay for ALP isoenzymes activity in human serum}

A screw-capped, $10 \mathrm{~mL}$, round-bottomed tube containing $1 \mathrm{~mL}$ of normal or abnormal serum was incubated in a shaking water bath at $37^{\circ} \mathrm{C}$. Incubations were initiated by the addition of retinoids, and aliquots $(50 \mu \mathrm{L})$ of control and chemical-treated serum were removed at $0,4,24,48$, and $72 \mathrm{~h}$, and used immediately or stored at $-20^{\circ} \mathrm{C}$. Mixtures of substrate buffer (disodiumphenylphosphate, $2 \mathrm{~mL}$ ) and serum $(50 \mu \mathrm{L})$ in a screw-capped, $10 \mathrm{~mL}$ round-bottomed tube were incubated for $15 \mathrm{~min}$ at $37^{\circ} \mathrm{C}$, followed by addition of color reagent (4-aminoantipyrine, $2 \mathrm{~mL}$ ), and color allowed to develop for $10 \mathrm{~min}$ at room temperature. The absorbance was measured within $60 \mathrm{~min}$ using a spectrophotometer (DR/4000U UV-Vis) at $570 \mathrm{~nm}$. All determinations were carried out in triplicate.

\section{Fluorescence detection assay for ALP isoenzymes activity in human serum}

A screw-capped, $10 \mathrm{~mL}$ round-bottomed tube containing $1 \mathrm{~mL}$ of normal or abnormal serum was incubated in a shaking water bath at $37^{\circ} \mathrm{C}$. Incubations were initiated by the addition of retinoids. Aliquots $(25 \mu \mathrm{L})$ of the control and chemical-treated serum were removed at $0,0.5,2,4$, and $24 \mathrm{~h}$, and used immediately or stored at $-20^{\circ} \mathrm{C}$. Normal and abnormal serum were treated with all-trans retinoic acids and 13-cis retinoic acids at concentrations $(1 \sim 5 \mathrm{mM})$. No chemical treatment controls were used. Mixtures containing 
dilution buffer $(25 \mu \mathrm{L})$, assay buffer $(97 \mu \mathrm{L})$, serum media (25 $\mu \mathrm{L}$ ), and 4-methylumbellifery phosphate (MUP, $1 \mathrm{mM}$, $3 \mu \mathrm{L}$ ) in a 96-well plate were incubated for $60 \mathrm{~min}$ in the dark at room temperature. The fluorescence of the ALP/ MUP product was measured using a 96-well plate fluorometer (Molecular Devices, F max) by excitation at $360 \mathrm{~nm}$, and emission at $449 \mathrm{~nm}$. All determinations were carried out in triplicate.

\section{Heat-sensitive inactivation}

Aliquots $(50 \mu \mathrm{L})$ of control and chemical-treated human serum were removed at $0,4,24,48$, and $72 \mathrm{~h}$, and heated for $5 \mathrm{~min}$ at $60 \sim 65^{\circ} \mathrm{C}$ in a water bath. The aliquots were used immediately for fluorescence assay of ALP activity, as described above.

\section{Wheat-germ lectin precipitation test}

A mixture of human serum $(1 \mathrm{~mL})$ and wheat-germ lectin $(1 \mathrm{mg} / 1 \mathrm{~mL})$ was incubated for $30 \mathrm{~min}$ at $37^{\circ} \mathrm{C}$, and centrifuged for $20 \mathrm{~min}$ at 3,000 rpm. The precipitate was suspended in phosphate-buffered saline ( $\mathrm{pH}$ 6.8) to generate $1 \mathrm{~mL}$ of solution. A screw-capped, $10 \mathrm{~mL}$ round-bottomed tube containing $1 \mathrm{~mL}$ of suspension was preincubated in a shaking water bath at $37^{\circ} \mathrm{C}$. Incubations were initiated by the addition of all-trans retinoic acid and 13-cis retinoic acid at a concentration of $5 \mathrm{mM}$. An aliquot $(25 \mu \mathrm{L})$ was subjected to fluorescence assay of ALP activity at the time points described above. The supernatant $(1 \mathrm{~mL})$ treated with retinoids was incubated, and an aliquot $(25 \mu \mathrm{L})$ was subjected to fluorescence assay of ALP activity at the time points described above.

\section{Statistical analysis}

Data are summarized as means \pm S.E. To analyze the data statistically, one-way analysis of variance (ANOVA) for repeated measurements of the same variable was performed. Duncan's multiple range $t$-test was then used to determine which means were significantly different from the mean of the control or chemical-treated serum. A significant difference in ALP activity between the control and chemical treated samples was indicated by $* P<0.01$.

\section{RESULTS}

\section{Effect of retinoids on tissue-specific chemical inhibited ALP activity}

To assay the activities of liver, bone, kidney, intestinal, and placental ALP isozymes in human serum, colorimetric and/or fluorescence detection assay methods were used (Moon, 2011). Retinoids, i.e., all-trans retinoic acid and 13-
A

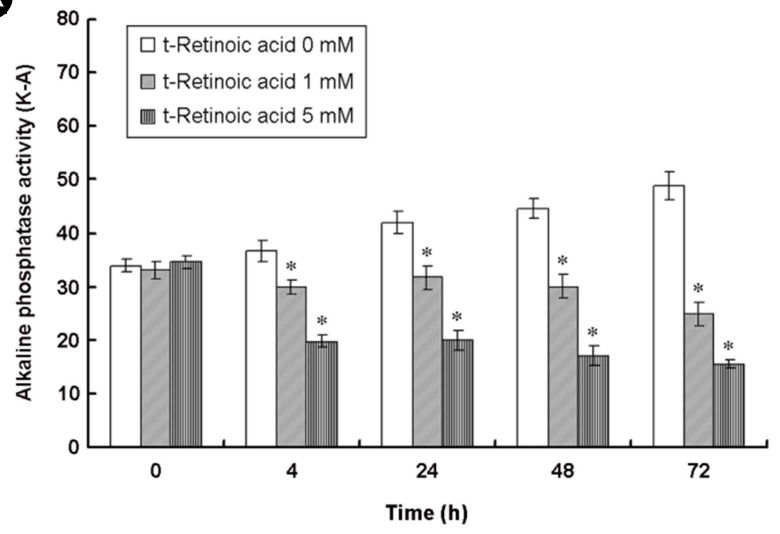

B

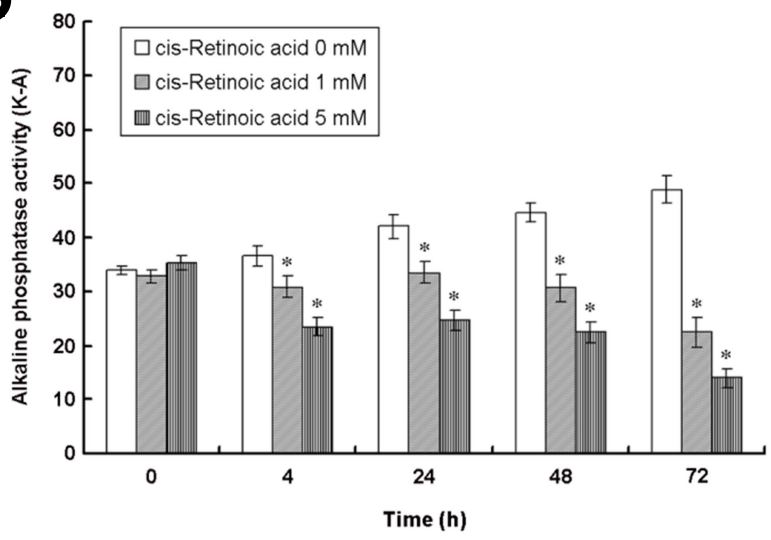

Fig. 1. Dose-dependent inhibitory effect of retinoic acid on alkaline phosphatase activity in abnormal human serum. A; All-trans retinoic acid effect on human serum ALP activity. B; 13-cis retinoic acid effect on human serum ALP activity. Each value represents the mean \pm S.E. of three independent determinations. K-A stands for King-Amstrong unit. A significant difference in ALP activity between the control and chemical treated samples was indicated by $* P<0.01$. 
cis retinoic acid, have no inhibitory effect on ALP activity in normal healthy human serum, but significantly inhibited the total ALP activity in abnormal human serum in a nonspecific as well as dose-dependent manner at concentrations of $1 \sim 5 \mathrm{mM}$ up to $72 \mathrm{~h}$ of incubation (Fig. 1A and B). These results led to examine the tissue-specific inhibitory effect of retinoids on ALP isoenzymes in human serum.

Alkaline phosphatase is present in human serum as liver, kidney, bone, intestinal, and placental-derived ALP isoenzymes (Shephard and Peake, 1986). It has been reported that in the human serum, isozyme ALP activity derived from bone, liver and intestine remained at $14 \%, 47 \%$ and $90 \%$, respectively, after treatment with guanidine hydrochloride (Shephard and Peake, 1986; Shephard et al., 1986), indicating that guanidine hydrochloride showed only slight inhibition of the intestinal ALP isoenzyme. All-trans retinoic acid (5 $\mathrm{mM})$ and 13-cis retinoic acid (5 $\mathrm{mM})$ inhibited ALP activities by up to $12 \%$ and $15 \%$, respectively, compared to that by guanidine hydrochloride (200 mM) (Fig. 2A and B). Thus, the inhibition by retinoids of ALP activities results mostly from inhibition of intestinal ALP.

L-phenylalanine is an effective inhibitor of intestinal

\section{A}

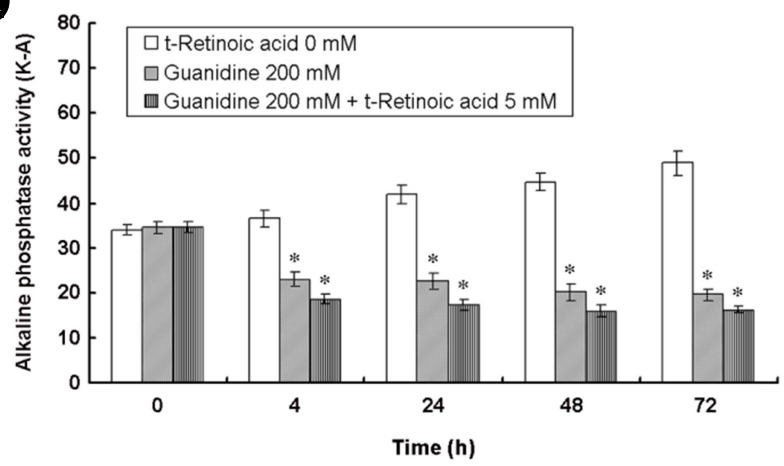

B

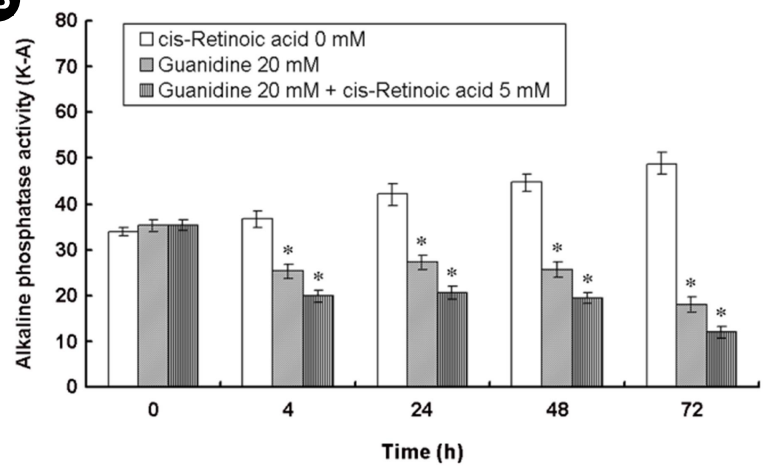

Fig. 2. Inhibitory effect of retinoic acid and guanidine on alkaline phosphatase activity in abnormal human serum. A; All-trans retinoic acid and guanidine effect on human serum ALP activity. B; 13-cis retinoic acid and guanidine effect on human serum ALP activity. Each value represents the mean \pm S.E. of three independent determinations. K-A stands for King-Amstrong unit. A significant difference in ALP activity between the control and chemical treated samples was indicated by $* P<0.01$.

A

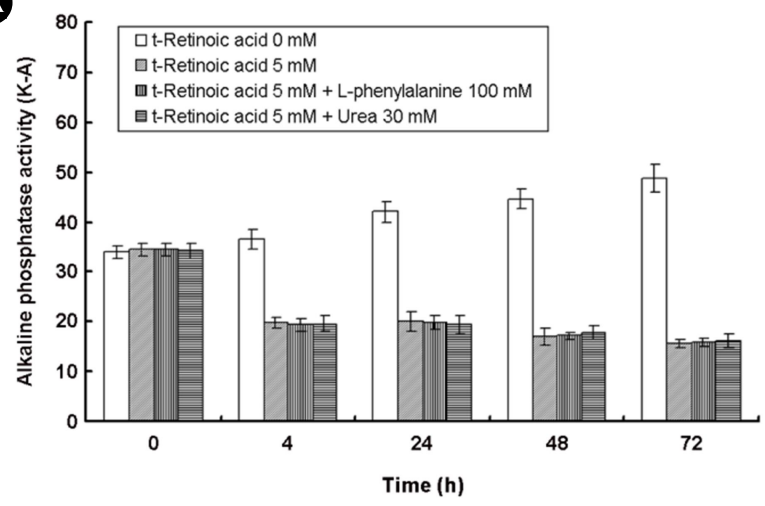

B

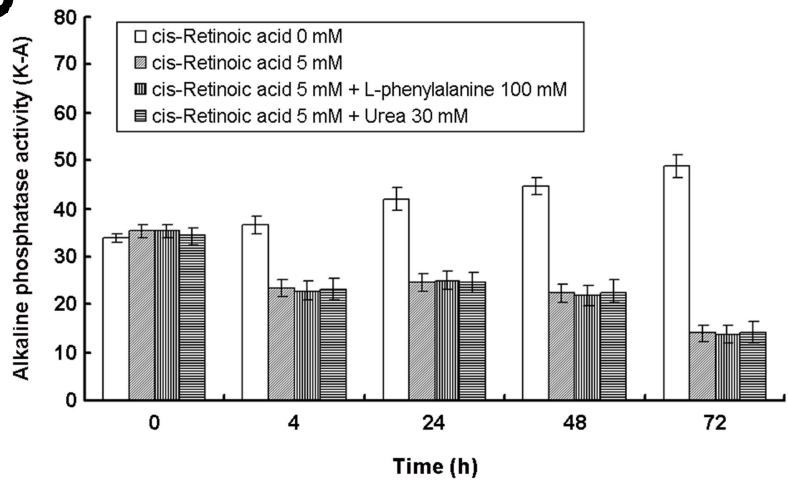

Fig. 3. No further inhibitory effect of retinoic acid, L-phenylalanine and urea on alkaline phosphatase activity in abnormal human serum. A; All-trans retinoic acid, L-phenylalanine and urea effect on human serum ALP activity. B; 13-cis retinoic acid, L-phenylalanine and urea effect on human serum ALP activity. Each value represents the mean \pm S.E. of three independent determinations. K-A stands for KingAmstrong unit. No significant difference in ALP activity was found between the retinoic acid and chemical treated retinoic acid samples. 
and placental-derived ALP isoenzymes, and inhibited the bone and liver-derived ALP isoenzymes to a lesser degree (Shephard and Peake, 1986; Shephard et al., 1986; Fishman and Sie, 1971). L-phenylalanine (100 mM) had no further inhibitory effect on ALP activities in human serum pretreated with retinoids (5 mM) (Fig. 3A and B). Retinoids (5 mM) also did not inhibit ALP activities in human serum pretreated with L-phenylalanine (100 mM) (Fig. 3A and B). Treatment of human serum with urea $(30 \mathrm{mM})$ resulted in inhibition of ALP activities similar to that of L-phenylalanine; therefore, ALP was inhibited by retinoids but not by phenylalanine or urea (Bahr and Wilkinson, 1967) (Fig. 3A and B).

The liver, kidney, and bone alkaline phosphatase isoenzymes are inhibited tetramisole (Van Belle et al., 1977). Alltrans retinoic acid $(5 \mathrm{mM})$ and 13 -cis retinoic acid $(5 \mathrm{mM})$ inhibited ALP activities by $18 \%$ and $20 \%$, respectively, compared to that by tetramisole (30 mM) (Fig. 4A and B), indicating that retinoids inhibited mainly the intestinal ALP
(4)

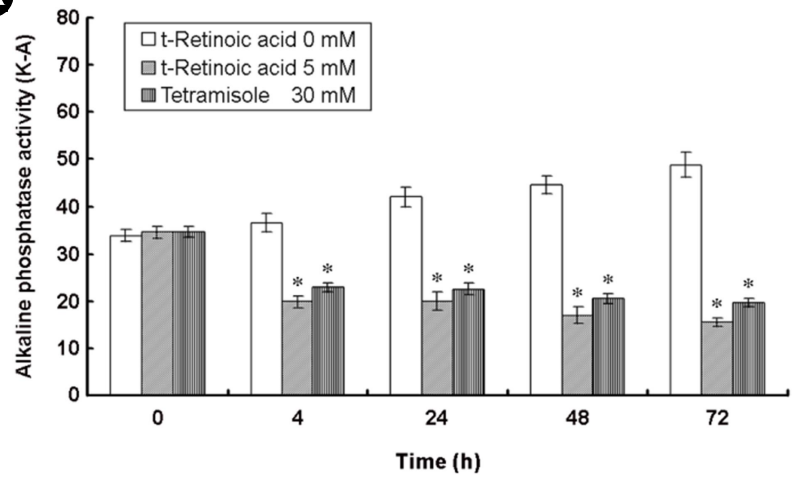

B

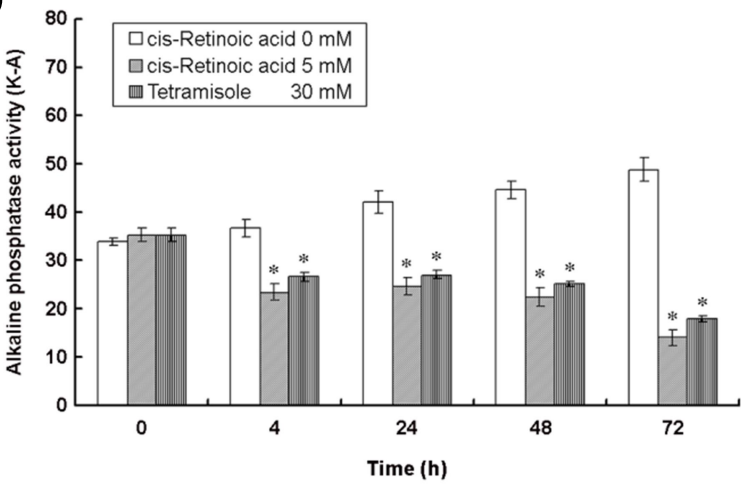

Fig. 4. Inhibitory effect of retinoic acid and tetramisole on alkaline phosphatase activity in abnormal human serum. A; All-trans retinoic acid and tetramisole effect on human serum ALP activity. B; 13-cis retinoic acid and tetramisole effect on human serum ALP activity. Each value represents the mean \pm S.E. of three independent determinations. K-A stands for King-Amstrong unit. A significant difference in ALP activity between the control and chemical treated samples was indicated by $* P<0.01$.

A

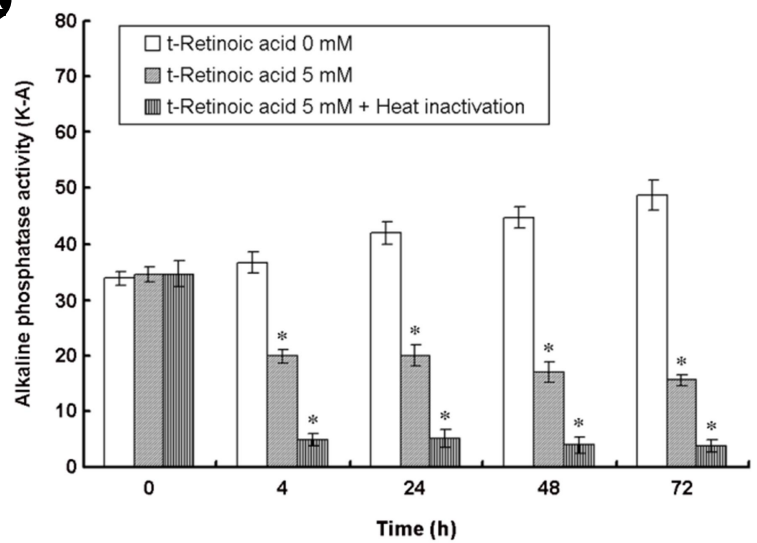

B

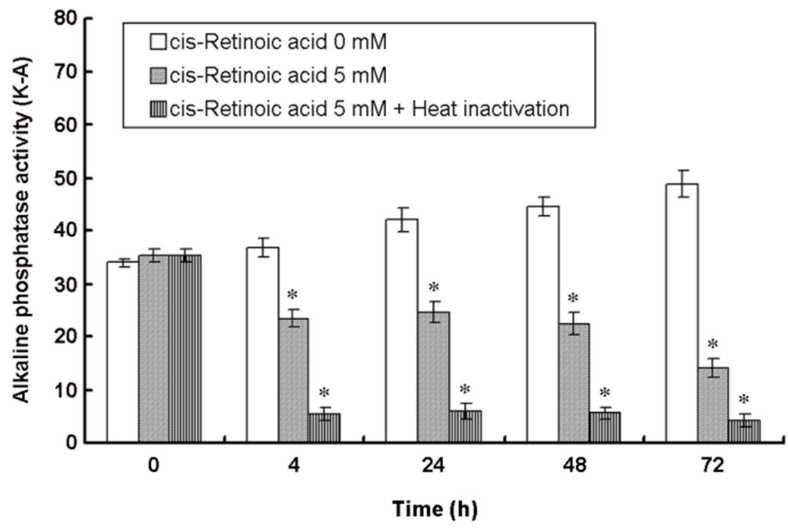

Fig. 5. Further inhibitory effect of retinoic acid and heat inactivation on alkaline phosphatase activity in abnormal human serum. A; Alltrans retinoic acid and heat inactivation effect on human serum ALP activity. B; 13-cis retinoic acid and heat inactivation effect on human serum ALP activity. Each value represents the mean \pm S.E. of three independent determinations. K-A stands for King-Amstrong unit. A significant difference in ALP activity between the retinoic acid and retinoic acid with heat inactivation samples was indicated by $* P<0.01$. 
(A)

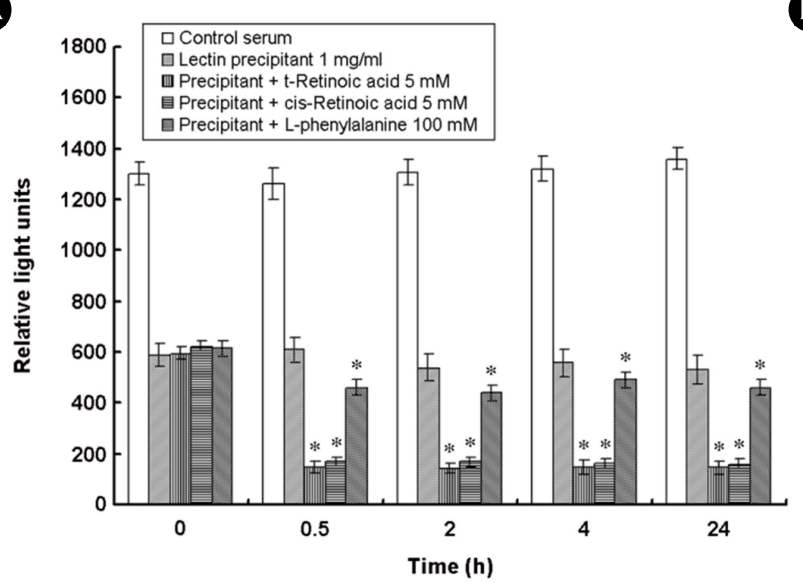

B

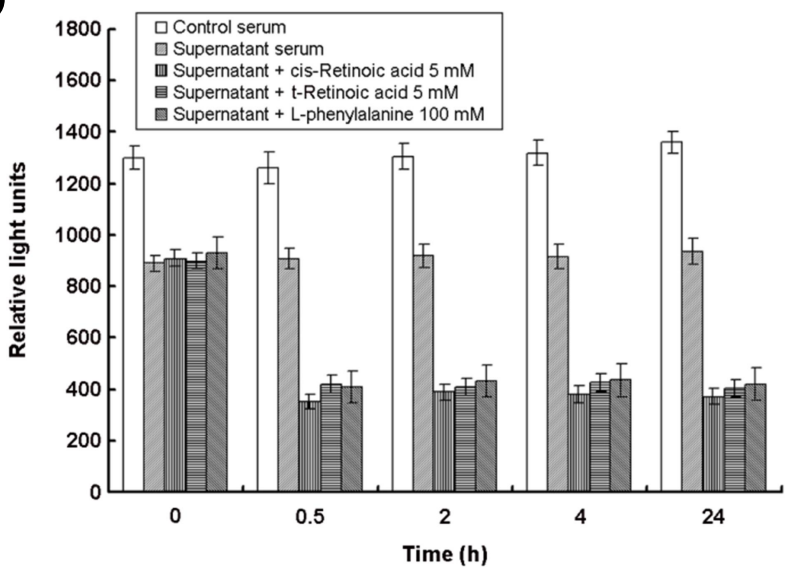

Fig. 6. Effect of retinoic acids and L-phenylalanine on lectin treatment alkaline phosphatase activity in abnormal human serum. A; Retinoic acids and L-phenylalanine effect on lectin precipitate human serum ALP activity. B; Retinoic acids and L-phenylalanine effect on lectin supernatant human serum ALP activity. Each value represents the mean \pm S.E. of three independent determinations. A significant difference in ALP activity between the lectin and chemical treated lectin samples was indicated by $* P<0.01$.

isozyme after tetramisole treatment (Fig. 4A and B).

\section{Effect of retinoids on heat-inactivated ALP activity}

Retinoid-pretreated serum was heat-inactivated and placental ALP activity determined (Neale et al., 1965). Heating at $60^{\circ} \mathrm{C}$ for $5 \mathrm{~min}$, reduced ALP activities by $75 \%$ compared to the control. These results suggest that only placental ALP activity remained, which was not inhibited by the placental ALP isoenzyme (Fig. 5A and B). These results further demonstrate that retinoids are predominant inhibitors of intestinal ALP isoenzyme activity in human serum.

\section{Effect of retinoids on wheat-germ lectin precipitated ALP activity}

ALP activities in the precipitate and supernatant after lectin treatment were measured to elucidate the effect of retinoids on bone-derived ALP isoenzyme activity as wheatgerm lectin precipitates bone ALP from human serum (Rosalki and Foo, 1984; Sørensen, 1988; Rosalki, 1994; Behr and Barnert, 1986; Burlina et al., 1991). Retinoids (5 mM) markedly inhibited ALP activity following precipitation by lectin, which indicates inhibition of principally the bone ALP isoenzyme (Fig. 6A). In serum supernatant, retinoids showed similar inhibition of total ALP activities to that by
L-phenylalanine (Fig. 6B). These results showed that retinoids inhibited the intestinal and bone ALP isoenzymes in human serum.

\section{DISCUSSION}

Retinoids possess a variety of pharmacological activities, such as immunomodulators, regulators of gene transcription, and tumor-suppressive agents with the potential for chemoprevention (Moon, 2007; Carratu et al., 2012; Lippman and Meyskens, 1987; Okuno et al., 2004; Lotan, 1996; Lippman et al., 1987; Altucci and Gronemeyer, 2001; Freemantle et al., 2003). The purpose of this study was to examine the effect of retinoids on human serum ALP activity for the discovering an inherent but unknown pharmacological activity elicited by retinoids. In this study, all-trans retinoic acid and 13-cis retinoic acid showed the significant inhibitory effect on the intestinal as well as the bone ALP isoenzymes.

Elevated human serum ALP activity is correlated with disease, and changes in ALP activity facilitate disease diagnosis. A progressive increase in serum bone ALP isoform activity was correlated with increased bone pain and progression of metastatic bone lesions in patients with bone cancer (Zaninotto et al., 1995; Burlina et al., 1994). There- 
fore, the inhibition of serum bone specific ALP activity by retinoids may facilitate monitoring and prevention of metastasis of bone cancer.

In conclusion, present findings suggest retinoids to be regulators of the activities of specific ALP isoenzymes and isoforms in human serum, which may be a valuable target for therapeutic interventions. We therefore suggest that further studies exploring the clinical usefulness of all-trans retinoic acid and 13-cis retinoic acid are conducted to evaluate whether they can serve as down regulators for bone cancer metastasis in conjunction with tumor-suppression and chemoprevention.

\section{ACKNOWLEDGEMENTS}

This study was supported by a grant from the GHU and IMHWAN Foundation to Dr. Ki-Young Moon.

\section{CONFLICT OF INTEREST}

No conflicts of interest, financial or otherwise, are declared by the authors.

\section{REFERENCES}

Altucci L, Gronemeyer H. The promise of retinoids to fight against cancer. Nature Reviews Cancer. 2001. 1: 181-193.

Bahr M, Wilkinson JH. Urea as a selective inhibitor of human tissue alkaline phosphatase. Clinica Chimica Acta. 1967. 17: 367-370.

Balmer JE, Blomhoff R. Gene expression regulation by retinoic acid. Journal of Lipid Research. 2002. 43: 1773-1808.

Behr W, Barnert J. Quantification of bone alkaline phosphatase in serum by precipitation with wheat-germ lectin: a simplified method and its clinical plausibility. Clinical Chemistry. 1986. 32: 1960-1966.

Burlina A, Plebani M, Secchiero S, Zaninotto M, Sciacovelli L. Precipitation method for separating and quantifying bone and liver alkaline phosphatase isoenzymes. Clinical Biochemistry. 1991. 24: 417-423.

Burlina A, Rubin D, Secchiero S, Sciacovelli L, Zaninotto M, Plebani M. Monitoring skeletal cancer metastases with the bone isoenzyme of tissue unspecific alkaline phosphatase. Clinica Chimica Acta. 1994. 226: 151-158.

Carratu MR, Marasco C, Mangialardi G, Vacca A. Retinoids: novel immunomodulators and tumour-suppressive agents? British Journal of Pharmacology. 2012. 167: 483-492.

Crofton PM. Biochemistry of alkaline phosphatase isoenzymes. Critical Reviews in Clinical Laboratory Sciences. 1982. 16: 161-194.

Darwiche N, Bazzi H, El-Touni L, Abou-Lteif G, Doueiri R, Hatoum A, Maalouf S, Gali-Muhtasib H. Regulation of ultraviolet B radiation-mediated activation of AP1 signaling by retinoids in primary keratinocytes. Radiation Research. 2005. 163: 296 -306 .

Dent CE, Norris TSM, Smith R, Sutton RAL, Temperley JM. Steatorrhea with striking increase of plasma alkaline phosphatase of intestinal origin. Lancet. 1968. 1: 1333-1336.

Epstein E, Kiechle FL, Artiss JD, Zak B. The clinical use of alkaline phosphatase enzymes. Clinics in Laboratory Medicine. 1986. 6: 491-505.

Ertesvag A, Naderi S, Blomhoff HK. Regulation of B cell proliferation and differentiation by retinoic acid. Seminars in Immunology. 2009. 21: 36-41.

Fishman WH, Sie HG. Organ-specific inhibition of human alkaline phosphatase isoenzymes of liver, bone, intestine and placenta: L-phenylalanine, L-tryptophan and L-homoarginine. Enzymologia. 1971. 41: 141-167.

Freemantle SJ, Spinella MJ, Dmitrovsky E. Retinoids in cancer therapy and chemoprevention: promise meets resistance. Oncogene. 2003. 22: 7305-7315.

Lippman SM, Kessler JF, Meyskens FL Jr. Retinoids as preventive and therapeutic anticancer agents (Part I). Cancer Treatment Reports. 1987. 71: 391-405.

Lippman SM, Meyskens FL Jr. Treatment of advanced squamous cell carcinoma of the skin with isotretinoin. Annals of Internal Medicine. 1987. 107: 499-502.

Lotan R. Retinoids in cancer chemoprevention. FASEB Journal 1996. 10: 1031-1039.

Moon KY. The chemopreventive effect of retinoids on cellular NF- $\kappa B$ activity induced by NMU and NEU in human malignant keratinocytes. Cancer Research and Treatment. 2007. 39: 82-87.

Moon KY. Acrolein, an I- $\mathrm{kB} \alpha$-independent downregulation of $\mathrm{NF}-\mathrm{\kappa B}$ activity, causes the decrease in nitric oxide production in human malignant keratinocytes. Archives of Toxicology. 2011. 85: 499-504

Moss DW. Alkaline phosphatase isoenzymes. Clinical Chemistry. 1982. 28: 2007-2016.

Neale FC, Clubb JS, Hotchkis D, Posen S. Heat stability of human 
placental alkaline phosphatase. Journal of Clinical Pathology. 1965. 18: 359-365.

Okuno M, Kojima S, Matsushima-Nishiwaki R, Tsurumi H, Muto Y, Friedman SL, Moriwaki H. Retinoids in cancer chemoprevention. Current Cancer Drug Targets. 2004. 4: 285-298.

Paillaud E, Costa S, Fages C, Plassat JL, Rochette-Egly C, Monville C, Tardy M. Retinoic acid increases proliferation rate of GL15 glioma cells, involving activation of STAT-3 transcription factor. Journal of Neuroscience Research. 2002. 67: 670-679.

Rosalki SB. Bone-origin alkaline phosphatase in plasma by wheatgerm lectin methods in bone disease. Clinica Chimica Acta. 1994. 226: 143-150.

Rosalki SB, Foo AY. Two new methods for separating and quantifying bone and liver alkaline phosphatase isoenzymes in plasma. Clinical Chemistry. 1984. 30: 1182-1186.

Seargeant LE, Stinson RA. Evidence that three structural genes code for human alkaline phosphatases. Nature. 1979. 281: 152 $-154$.

Shephard MDS, Peake MJ. Quantitative method for the determination of serum alkaline phosphatase isoenzyme activity I. Guanidine hydrochloride: a new reagent for selectively inhibiting the major serum isoenzymes of alkaline phosphatase. Journal of Clinical Pathology. 1986. 39: 1025-1030.

Shephard MDS, Peake MJ, Walmsley RN. Quantitative method for determining serum alkaline phosphatase isoenzyme activity II. Development and clinical application of method for measuring four serum alkaline phosphatase isoenzymes. Journal of Clinical Pathology. 1986. 39: 1031-1038.

Stolbach LL, Krant MJ, Inglis NR, Fishman WH. Correlation of serum L-phenylalanine-sensitive alkaline phosphatase derived from intestine with $\mathrm{ABO}$ blood group of cirrhotics. Gastroenterology. 1967. 52: 819-827.

Sørensen S. Wheat-germ agglutinin method for measuring bone and liver isoenzymes of alkaline phosphatase assessed on postmenopausal osteoporosis. Clinical Chemistry. 1988. 34: 1636-1640.

Van Belle H, De Broe ME, Wieme RJ. L-p-Bromotetramisole, a new reagent for use in measuring placental or intestinal isoenzymes of alkaline phosphatase in human serum. Clinical Chemistry. 1977. 23: 454-459.

Walker AW. Intestinal alkaline phosphatase in serum of patients on maintenance haemodialysis. Clinica Chimica Acta. 1974. 55: 399-405.

Zaninotto M, Secchiero S, Rubin D, Sciacovelli L, Trovo M, Bortolus R, Plebani M. Serum bone alkaline phosphatase in the follow-up of skeletal metastases. Anticancer Research. 1995. 15: 2223-2228.

https://doi.org/10.15616/BSL.2017.23.3.230

Cite this article as: Kim SH, Moon KY. Inhibitory Effect of Retinoids on Alkaline Phosphatase Isoenzymes Activity in Human Serum. Biomedical Science Letters. 2017. 23: 230-237. 